\title{
Protective Features of Autophagy in Pulmonary Infection and Inflammatory Diseases
}

\author{
Kui Wang ${ }^{1,2,+}$, Yi Chen ${ }^{3,+}$, Pengju Zhang ${ }^{1}$, Ping Lin ${ }^{2}$, Na Xie ${ }^{1,4, *}$ and $\mathrm{Min} \mathrm{Wu}^{2, *}$ \\ 1 West China School of Basic Medical Sciences \& Forensic Medicine, and State Key Laboratory of Biotherapy, \\ Sichuan University, and Collaborative Innovation Center for Biotherapy, Chengdu 610041, China; \\ wangkui416@163.com (K.W.); zhangpengju526@163.com (P.Z.) \\ 2 Department of Biomedical Sciences, University of North Dakota, Grand Forks, ND 58203, USA; \\ bio_lp@126.com \\ 3 Department of Gastrointestinal Surgery, State Key Laboratory of Biotherapy, Sichuan University, \\ Chengdu 610041, China; toddychan@163.com \\ 4 Section of Infection and Immunity, Herman Ostrow School of Dentistry, Norris Comprehensive Cancer \\ Center, University of Southern California, Los Angeles, CA 90089-0641, USA \\ * Correspondence: xnshina@126.com (N.X.); min.wu@med.und.edu (M.W.); \\ Tel.: +86-158-8455-5293 (N.X.); +1-(701)-777-4875 (M.W.) \\ + These authors contributed equally to this work.
}

Received: 31 December 2018; Accepted: 31 January 2019; Published: 3 February 2019

check for updates

\begin{abstract}
Autophagy is a highly conserved catabolic process involving autolysosomal degradation of cellular components, including protein aggregates, damaged organelles (such as mitochondria, endoplasmic reticulum, and others), as well as various pathogens. Thus, the autophagy pathway represents a major adaptive response for the maintenance of cellular and tissue homeostasis in response to numerous cellular stressors. A growing body of evidence suggests that autophagy is closely associated with diverse human diseases. Specifically, acute lung injury (ALI) and inflammatory responses caused by bacterial infection or xenobiotic inhalation (e.g., chlorine and cigarette smoke) have been reported to involve a spectrum of alterations in autophagy phenotypes. The role of autophagy in pulmonary infection and inflammatory diseases could be protective or harmful dependent on the conditions. In this review, we describe recent advances regarding the protective features of autophagy in pulmonary diseases, with a focus on ALI, idiopathic pulmonary fibrosis (IPF), chronic obstructive pulmonary disease (COPD), tuberculosis, pulmonary arterial hypertension (PAH) and cystic fibrosis.
\end{abstract}

Keywords: Autophagy; inflammation; acute lung injury; idiopathic pulmonary fibrosis; COPD; tuberculosis; PAH; cystic fibrosis

\section{Introduction}

Macroautophagy (henceforth referred to as autophagy) is an evolutionarily conserved process by which intracellular materials are sequestered by double-membrane autophagosomes and then delivered to lysosomes for degradation and recycling in various physiological and pathological conditions [1]. The degradation substrates include aggregate-prone proteins, lipids, organelles (including mitochondria, endoplasmic reticulum, peroxisomes, etc.), and intracellular pathogens (bacteria and viruses) [2,3]. The digestion of these autophagy cargoes can maintain cellular homeostasis by facilitating the quality control of the cytoplasm, recycling intracellular components (amino acids, fatty acids, and carbohydrates) to fuel anabolic pathways and energy generation, or by enabling pathogen clearance [2,4]. Therefore, the autophagy process appears to serve as a cellular protective mechanism to counter diverse diseases, including cancer, neurodegenerative diseases, and infectious diseases $[3,5]$. Conversely, dysregulation 
of autophagy is also known to exacerbate the disease progression under certain conditions, suggesting that the role of autophagy in human diseases is complex [3,5].

The lung is the primary organ for gas exchange, delivering $\mathrm{O}_{2}$ from the atmosphere to the bloodstream and releasing $\mathrm{CO}_{2}$ into the atmosphere. During respiration, the lung is continuously exposed to various harmful environmental stimuli, including pathogens (such as viruses and bacteria) and xenobiotics (such as cigarette smoke and particles) [6]. Acute or chronic exposure to these harmful agents can cause damage to the lung, resulting in respiratory dysfunction and pulmonary diseases $[6,7]$. Both acute lung injury (ALI) and chronic pulmonary diseases are associated with high morbidity and mortality with limited effective therapeutics, thus representing major public health problems worldwide $[7,8]$. In coping with these outside threats, the lung has evolved various defense mechanisms (such as innate and adaptive immune responses) to maintain its normal function. During the past decade, altered autophagy phenotypes in lung cells have been observed in response to these harmful stimuli [9]. Autophagy is capable of eliminating pathogens, degrading damaged organelles, and regulating inflammatory responses or apoptosis. Thus, autophagy is primarily characterized as a novel defense mechanism for lung injury [10-12]. However, autophagy dysfunction has also been reported to represent a harmful event that promotes the progression of pulmonary diseases [11,12]. This seemingly contradictory role of autophagy in pulmonary diseases underlies the lack of an in-depth understanding of the complex autophagy mechanisms in lung injury and pulmonary diseases. In this review, we will summarize the current knowledge of the protective features of autophagy in pulmonary infection and inflammatory diseases, and discuss the perspective of targeting autophagy for the clinical intervention for lung diseases.

\section{Molecular Regulation of the Autophagy Process}

The autophagy process involves a sequence of molecular events, including initiation (the formation of phagophore), elongation/closure (the formation of autophagosome), and maturation (the fusion of autophagosome with lysosome) [5] (Figure 1). The initiation of autophagosome biogenesis is triggered by the activation of the UNC51-like kinase (ULK) complex (also called the preinitiation complex), which is composed of ULK1/2, ATG13, FIP200, and ATG101 [4]. The ULK complex can be activated by inactivation of the mammalian target of rapamycin complex 1 (mTORC1), in response to nutrient starvation or the activation of $5^{\prime}$-AMP-activated protein kinase (AMPK) under energy-deprived conditions, to transmit stress signals for autophagosome formation [13]. Meanwhile, in addition to AMPK and mTORC1, the activity of the ULK complex can be regulated by other signals [4]. In turn, the activation of the ULK complex stimulates the class III phosphatidylinositol-3-kinase (class III PI3K) complex (also termed the VPS34 complex or initiation complex), which consists of VPS34, VPS15, Beclin 1, ATG14L, and AMBRA1 [14]. The dissociation of Beclin 1 from Bcl-2/xL anti-apoptotic proteins is a prerequisite for the formation and activation of the class III PI3K complex [14]. This class III PI3K complex enables the conversion of phosphatidylinositol to generate phosphatidylinositol-3-phosphate (PI3P) required for the nucleation of phagophore [15].

The phagophore then elongates and closes up to form the double-membrane autophagosome, which is tightly regulated by PI3P-binding proteins, such as the WD-repeat protein interacting with phosphoinosides (WIPI) family of proteins and two ubiquitin-like (UBL) protein conjugation systems. The completion of the first ubiquitin-like conjugation system leads to the formation of the ATG12/ATG5/ATG16L1 complex, which marks the sites of autophagosome formation and acts as a E3-like ligase for the second conjugation system to generate LC3-II (LC3-PE, the phosphatidylethanolamine-conjugated LC3) from the ATG4-mediated proteolytic cleavage of LC3 $[4,16]$. The lipidated LC3-II is closely associated with the elongation of the phagophore for autophagosome formation [17]. Following the completion of autophagosome formation, the autophagosome will fuse with a lysosome to form an autolysosome, in which the sequestered contents are degraded by a variety of lysosomal acid hydrolases and released into the cytosol for recycling $[18,19]$. 


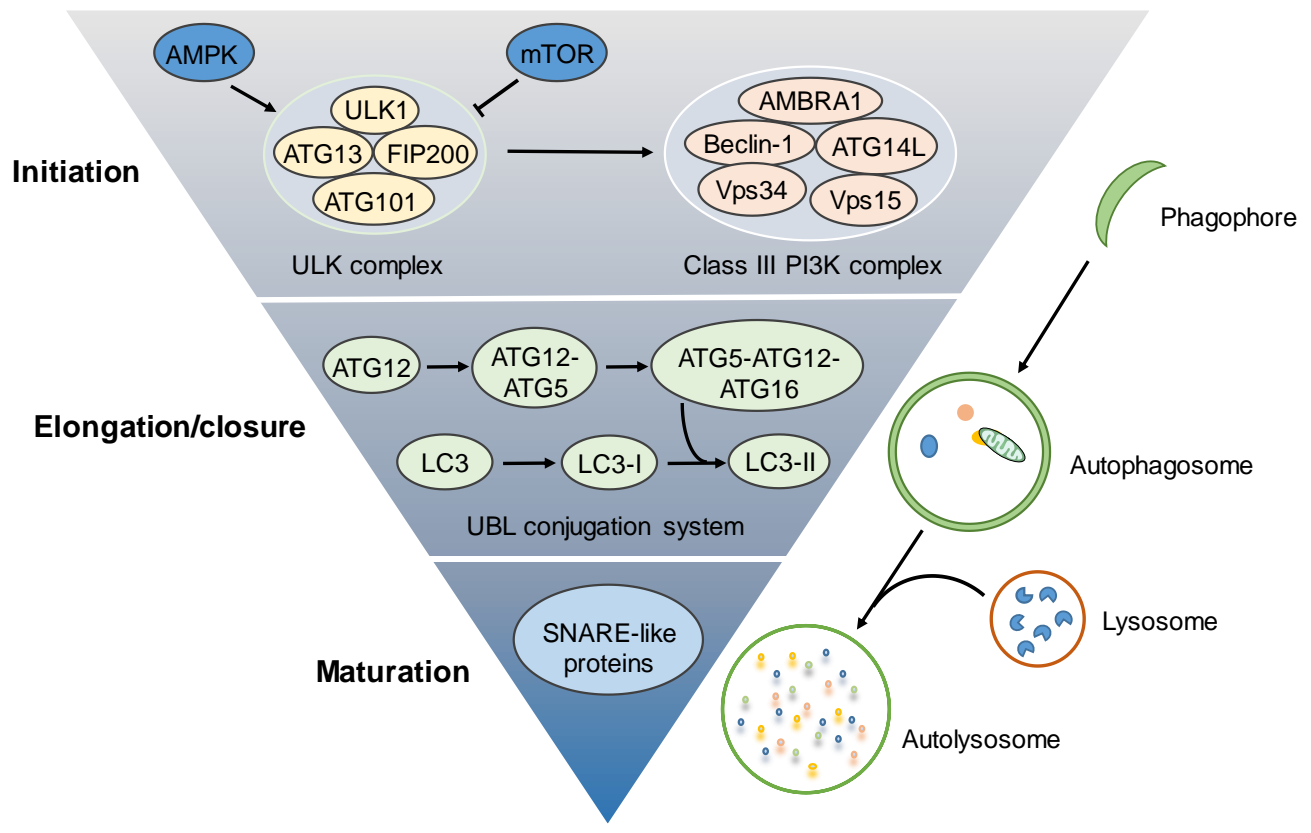

Figure 1. Autophagy machinery. The autophagy process involves initiation, elongation/closure and maturation. The autophagy process is initiated by autophagosome biogenesis to form phagophore, which is regulated by the activation of the preinitiation complex (also known as the ULK complex, containing ULK1/2, ATG13, FIP200, and ATG101) and subsequent activation of the initiation complex (also called the class III PI3K complex, consisting of VPS34, VPS15, Beclin 1, ATG14L, and AMBRA1). The phagophore is then elongated and closed to form a double-membrane autophagosome, which is tightly regulated by the ubiquitin-like (UBL) conjugation systems. The autophagosome will fuse with a lysosome to form an autolysosome for degradation. The SNARE-like proteins may play important roles in autophagosome-lysosome degradation. AMPK-5'-AMP-activated protein kinase; mTOR — the mammalian target of rapamycin; ULK1-UNC51-like kinase 1; class III PI3K—the class III phosphatidylinositol-3-kinase.

Autophagy-mediated degradation was previously recognized as a nonspecific process to remove cellular debris. Recently, increasing evidence suggests that autophagic encapsulation and degradation in some cases could be highly selective for specific substrates (termed 'selective autophagy') [2,3]. For example, autophagy can selectively digest damaged or depolarized mitochondria for the maintenance of mitochondrial homeostasis (mitophagy), remove invading pathogens (i.e., bacteria) to enhance host defense (xenophagy), clear polyubiquitinated protein for protein turnover (aggrephagy), and so on $[12,20,21]$. These types of selective autophagy act as cell survival mechanisms in most cases and are reported to play protective roles in pulmonary infection and inflammatory diseases [22]. Interestingly, mitophagy might also be cytotoxic if it is excessively induced to degrade even functional mitochondria [23,24]. In addition, emerging studies found that several pathogens, such as hepatitis B virus or hepatitis $C$ virus, can adapt to autophagy induction, or even employ autophagy machinery to facilitate their replication [25-27]. The length of airway epithelial cilia can also be regulated by autophagic degradation (ciliophagy) [12]. Cilia shortening, mediated by ciliophagy, can impair the clearance ability of the airway against invading pathogens, thereby exacerbating pulmonary infection $[28,29]$. The double-edged sword role of autophagy in pulmonary diseases might be attributed to different cell types and different types of diseases.

\section{The Protective Roles of Autophagy in Acute Lung Injury (ALI)}

Acute lung injury (ALI) is a common and severe clinical syndrome with high morbidity and mortality [7]. ALI is characterized with increased alveolar-capillary permeability, noncardiogenic pulmonary edema, neutrophil recruitment and diffuse alveolar damage, and represents a major cause 
of acute respiratory failure $[11,30]$. The intrapulmonary inflammatory response with the release of proinflammatory cytokines could be observed before and during the process of ALI, and has been intensively investigated recently [30,31]. However, the mechanisms underlying the pathogenesis and resolution of ALI remain largely unclear. Accumulating evidence suggests that autophagy is stimulated in response to diverse stimuli of ALI, including bacterial infection, lipopolysaccharide (LPS), sepsis, hyperoxia, and chlorine, etc. [32]. In addition, the loss of autophagy-related (ATG) genes, such as Atg7, Atg5 and Atg4b, significantly aggravates the development of ALI in mice [11,32], suggesting that autophagy may exert protective effects for the initiation and progression of ALI in certain contexts (Figure 2).

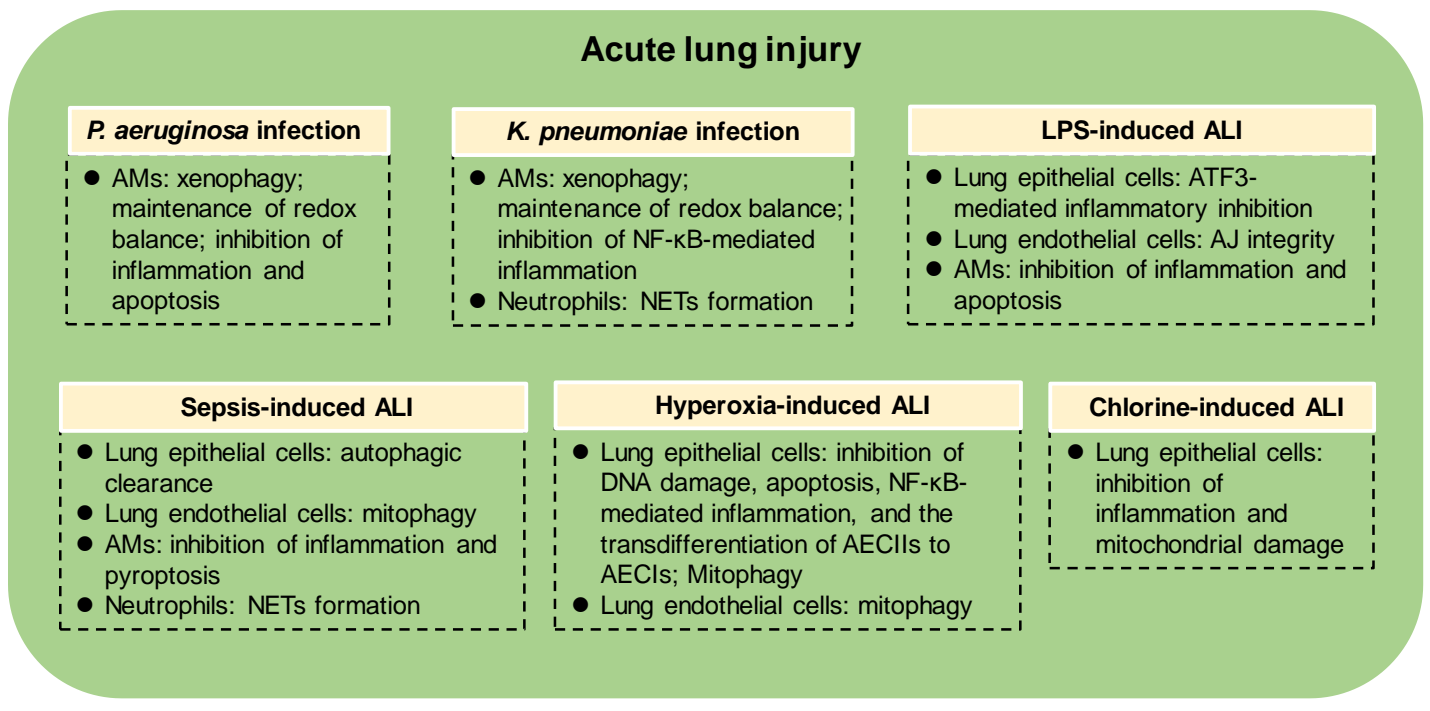

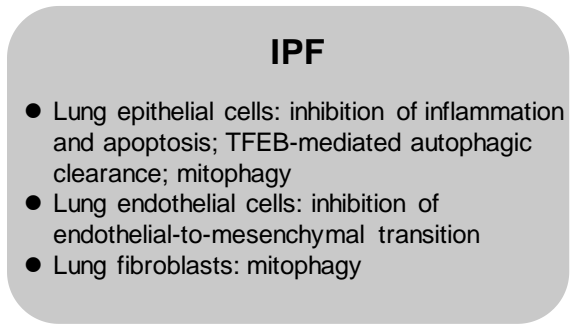

\section{Tuberculosis}

- AMs: bacterial clearance (xenophagy); inhibition of inflammation

- Monocytes, dendritic cells and lung epithelial cells: bacterial clearance

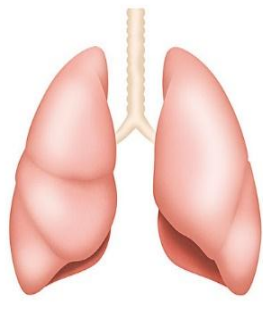

PAH

Pulmonary artery endothelial cells: inhibition of ROS production and promotion of HIF-1a degradation

\section{COPD}

- Lung epithelial cells: inhibition of cellular senescence; mitophagy; TFEB-mediated aggrephagy

- AMs: xenophagy (facilitating recurrent infections)

Figure 2. The protective mechanisms of autophagy in lung diseases. Autophagy may provide a protective role in the pathogenesis of various lung diseases (including ALI, IPF, COPD, tuberculosis, $\mathrm{PAH}$, cystic fibrosis, etc.), through regulating diverse biological events, including inflammatory response, redox balance, DNA damage repair, apoptosis, pyroptosis, cellular senescence, NETs formation, mitochondrial homeostasis, pathogen or aggresome clearance, etc. ALI-acute lung injury; IPF—idiopathic pulmonary fibrosis; COPD—chronic obstructive pulmonary disease; PAH—pulmonary arterial hypertension; TFEB — transcription factor EB; AMs—alveolar macrophages; NETs—neutrophil extracellular traps; AJ integrity-adherens junctional integrity; P. aeruginosa-Pseudomonas aeruginosa; K. pneumoniae-Klebsiella pneumoniae; LPS-lipopolysaccharide.

\subsection{The Protective Roles of Autophagy in Bacteria-Induced ALI}

Pseudomonas aeruginosa (P. aeruginosa), an opportunistic Gram-negative human pathogen, was reported to induce autophagosome formation and subsequent autolysosomal degradation in alveolar 
macrophages (AMs), which are known as part of the first line of host defense in the lung [33]. The P. aeruginosa-induced autophagy is partially mediated by the Annexin A2 (ANXA2)-Akt1-mTORULK1/2 and Beclin-1-ATG7-ATG5 signaling pathways [33,34]. Anxa2 knockout mice exhibit elevated inflammatory cytokines, decreased bacterial clearance, increased lung injury and mortality [34]. How autophagy enhances host defense against $P$. aeruginosa remains largely to be investigated. We have recently found that following P. aeruginosa infection, toll-like receptor 2 (TLR2) initiates the phagocytic process in AMs and activates the Src kinase Lyn, which in turn delivers bacteria to lysosomes for degradation through xenophagy [35]. In addition to Lyn, the Wnt5A-Rac1-Disheveled pathway is also required for inducing xenophagy in AMs [36]. We also reported that regulation of redox balance and inflammatory response is involved in autophagy-mediated eradication of P. aeruginosa. Atg7 deficiency promotes the release of reactive oxygen species (ROS) but limits NO production through inhibiting JAK2/STAT1 $\alpha /$ NOS2 signaling, leading to the intracellular redox imbalance, elevated inflammatory cytokines, enhanced apoptosis of AMs, exaggerated lung infection and aggravated lung injury in mice [37]. Interestingly, P. aeruginosa-mediated autophagy induction and inflammasome activation can be mutually regulated to subtly orchestrate the host defense. For example, $P$. aeruginosa infection triggers protective autophagy by activating TLR4-TRIP signaling in bone marrow-derived macrophages (BMDMs). Meanwhile, the NLRC4 inflammasome can be activated, leading to caspase-1-mediated TRIF cleavage, and subsequent autophagy inhibition, thereby reducing bacterial clearance [38]. Autophagy, in turn, abrogates the activation of NLRC4 inflammasome by selectively removing damaged mitochondria (mitophagy) in BMDMs, leading to increased bacterial clearance [39]. Thus, autophagy induction and NLRC4 inflammasome activation may constitute a negative feedback loop in BMDMs following $P$. aeruginosa infection, which might facilitate the development of novel therapeutic options for the treatment of $P$. aeruginosa infection. However, whether this negative feedback loop is present in P. aeruginosa-infected AMs remains to be further investigated.

Klebsiella pneumoniae (K. pneumoniae) is another Gram-negative bacterium that can activate the autophagy process in AMs [40]. It has been reported that Atg7 deficiency significantly elevates the levels of inflammatory cytokines and superoxide, leading to increased susceptibility to K. pneumoniae infection in mice, suggesting that ATG7-mediated autophagy may represent a major resistance mechanism to K. pneumoniae infection [40]. Further study found that ATG7 can directly bind phosphorylated

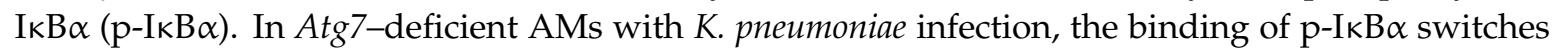
from ATG7 to ubiquitin, leading to the ubiquitin-mediated degradation of $\mathrm{I} \kappa \mathrm{B} \alpha$, activation of NF- $\mathrm{k} B$, intensified inflammation, and decreased bacterial clearance [41]. Similar to P. aeruginosa infection, the TLR2-Lyn- or Wnt5A-Rac1-Disheveled-mediated xenophagy in AMs also contributes to the degradation and clearance of K. pneumoniae $[35,36]$. In addition to AMs, neutrophils also play important roles in the anti-bacterial host defense in the lung. In response to bacterial infection, the recruited neutrophils can release decondensed chromatin fibrils to form neutrophil extracellular traps (NETs) in a highly oxidative milieu, in order to trap, neutralize, and destroy microbes extracellularly [42]. It has been reported that TRPM2-AMPK-p38- or Mincle-mediated induction of autophagy is required for NETs formation following K. pneumoniae infection in a ROS-dependent or independent manner, respectively $[43,44]$. Future studies are needed for understanding the molecular mechanism underlying autophagy-regulated NETs formation during bacterial infection.

\subsection{The Protective Roles of Autophagy in LPS-Induced ALI}

The outer membrane of Gram-negative bacteria is composed predominantly of LPS (also known as endotoxin), which is a pathogen-associated molecular pattern (PAMP) that enables the recognition of bacterial invasion and activates innate immune system [45]. It has been reported that LPS stimulation can regulate autophagy in lung epithelial cells, pulmonary endothelial cells and AMs. For example, LPS induces autophagy in mice lung tissues and bronchial epithelial cells. Atg $4 b$ deficiency significantly increases the susceptibility of the lung to LPS-mediated injury by impairing ATF3 activity, suggesting a protective role of autophagy in LPS-induced lung injury [46]. The LPS-induced protective autophagy 
may be due to the involvement of endoplasmic reticulum (ER) stress [47]. Interestingly, LPS was also reported to inhibit autophagy through TLR4- or AMPK inactivation-mediated mTOR activation in bronchial or alveolar epithelial cells [48,49]. MTOR knockdown, AMPK activation or autophagy stimulation significantly attenuates LPS-induced airway inflammation and injury, suggesting that autophagy functions as a protective mechanism to LPS-induced lung injury [48,49]. The inconsistent effects of LPS on the induction of autophagy may be due to different cell types and different sources of LPS. Despite this inconsistency, it can be concluded that autophagy in general confers a cytoprotective role in LPS-induced lung injury.

In addition to lung epithelial cells, LPS also induces autophagy in pulmonary endothelial cells. The inhibition of autophagy by siATG5, siATG7 or chloroquine markedly reduces the permeability of human pulmonary microvascular endothelial cells and attenuates LPS-induced lung injury in mice, in part through restricting the injury of lung microvascular barrier, suggesting a protective role of autophagy in LPS-induced lung injury [50]. Mechanistically, RAB26, a newly identified small GTPase, can induce autophagic degradation of active SRC and the resultant CDH5 dephosphorylation, leading to the maintenance of lung vascular permeability and the protection of adherens junctional integrity in LPS-induced ALI [51]. In contrast, it was reported in another recent study that the inhibition of autophagy by 3-methyladenine (3-MA) significantly disrupts the endothelial barrier in human pulmonary artery endothelial cells and ameliorates lung vascular injury upon LPS treatment, suggesting that autophagy promotes LPS-induced lung injury [52]. This contradictory outcome of autophagy in LPS-induced lung injury might be due to the use of different autophagy inhibitors in different types of endothelial cells.

LPS was also reported to induce autophagy in macrophages during LPS treatment. In response to LPS stimulation, the activated calcium/calmodulin-dependent protein kinase I $\alpha$ (CaMKI $\alpha$ ) can phosphorylate AMPK to form the CaMKI $\alpha$-AMPK-ATG7 complex that contributes to autophagy induction in an mTOR-independent manner. The CaMKI $\alpha$-AMPK-ATG7 signaling-mediated autophagy markedly attenuates LPS-induced lung neutrophilic inflammation [53]. Stimulation of autophagy by BML-111, a lipoxin A4 receptor agonist, significantly inhibits apoptosis, reduces the levels of proinflammatory cytokines, and ameliorates the LPS-induced lung injury [54]. These studies suggest that autophagy in macrophages confers the resolution of LPS-induced ALI, and may represent a potential therapeutic target.

\subsection{The Protective Roles of Autophagy in Sepsis-Induced ALI}

Sepsis is a syndrome of excessive inflammatory response to infection with high morbidity commonly leading to ALI [55]. However, the pathogenesis of sepsis still remains largely unclear. Emerging evidence suggests a critical role of autophagy in preventing sepsis, and the modulation of autophagy may provide novel insights for the treatment of sepsis. For example, in the cecal ligation puncture (CLP) - induced sepsis mice model, the levels of LC3-II, ATG5, and ATG7 are downregulated in the lung of mice with sepsis, suggesting that sepsis may suppress autophagy. Stimulation of autophagy using rapamycin or activated protein C (APC) results in reduced inflammation and attenuated lung injury [56]. Interestingly, another group found that the LC3-II level is markedly increased in the lung of septic mice. The increased LC3-II level is due to autophagosome accumulation caused by the retarded autophagosome-lysosome fusion. Transgenic mice overexpressing the LC3 gene exhibit accelerated fusion of autophagosome with lysosome, and survive longer after CLP [57]. This study suggests that the role of autophagy in CLP-induced sepsis might depend on the autophagic flux: the preservation of autophagic flux is cytoprotective to sepsis, while autophagosome accumulation due to impaired autophagic flux may contribute to lung injury in the late stage of sepsis. The discrepancy in LC3-II level observed in the same sepsis model in these two studies may be due to the ignorance of the LC3-II/LC3-I ratio, or the different detection time periods.

Mitochondrial dysfunction is recognized as an important mediator of sepsis pathogenesis. It was recently shown that the deficiency of kinase MKK3 ameliorates mitochondrial injury by 
lowering ROS levels and stimulating mitophagy, and increases mitochondrial biogenesis in pulmonary endothelial cells, leading to reduced septic lung injury [58]. Although the mechanism underlying the upstream signaling for mitophagy initiation remains to be defined, mitophagy may help provide novel therapeutic window for the treatment of sepsis. In addition to mitochondrial quality control, autophagy can also regulate inflammasome during sepsis. In a P. aeruginosa-induced sepsis mice model, Atg7 deficiency significantly intensifies inflammasome activation and provokes pyroptosis in AMs, leading to impaired pathogen clearance and aggravated lung injury [59]. In addition, autophagy was found to be activated in neutrophils from both patients who survived sepsis or septic mice. Interestingly, autophagy augmentation in neutrophils leads to the formation of NETs in order to protect mice from lethal sepsis [60].

Considerable efforts have been made to develop autophagy-modulating strategies for the treatment of sepsis. For example, miR-155 was found to induce autophagy by inhibiting transforming growth factor- $\beta$ (TGF- $\beta$ )-activated kinase-1-binding protein 2 (TAB2), resulting in the alleviation of inflammation in septic lung injury [61]. In addition, it has been reported that the clinically approved anthracyclines at low doses can effectively confer disease tolerance to severe sepsis in mice via activation of DNA damage response and the stimulation of autophagy pathways in the lung [62]. Notably, carbon monoxide (CO) administered at low physiologic doses was reported to promote the Beclin 1-dependent autophagy process in lung epithelial cells through mitochondrial ROS generation, thereby increasing the survival of septic mice $[63,64]$. These studies suggest that CO exhibits a protective effect on sepsis, supporting the potential therapeutic application of $\mathrm{CO}$ for sepsis treatment.

\subsection{The Protective Roles of Autophagy in Hyperoxia-Induced ALI}

Hyperoxia (high levels of oxygen) exposure is commonly used for critically ill patients, including those with acute respiratory distress syndrome and chronic obstructive pulmonary disease (COPD) [65]. However, prolonged hyperoxia treatment induces the generation of excessive ROS, DNA damage and inflammatory response, leading to ALI and even respiratory failure [66]. The injury of pulmonary epithelium and subsequent apoptotic cell death is one of the major effects of hyperoxia [66]. It has been reported that hyperoxia upregulates ATG7, and induces LC3 turnover and autophagosome formation by activating c-Jun N-terminal kinase (JNK). Under hyperoxia, LC3 can interact with Fas by associating with caveolin-1 in lipid rafts to prevent apoptosis facilitating the survival of lung epithelial cells [67]. The hyperoxia-induced increased interaction of LC3 with Fas is due to the dissociation of LC3 with p62, an autophagic adaptor linking ubiquitinated substrates to the autophagy pathway for degradation [68]. Hyperoxia-mediated LC3 activation was also found to promote the accumulation of surfactant protein C (SP-C) in type II alveolar epithelial cells (AECIIs) and inhibit the transdifferentiation of AECIIs to type I alveolar epithelial cells (AECIs) [69,70]. In addition, hyperoxia-induced ROS accumulation causes DNA damage in lung epithelial cells, which could be repaired by 8-oxoguanine-DNA glycosylase (OGG-1). Through regulating ATG7 promoter, OGG-1 links DNA damage with autophagy in stimulating NF- $k B-$ mediated inflammatory response to protect hyperoxia-induced epithelial injury [71]. Hyperoxia also causes a morphological change in mitochondria accomplished with increased expression of mitophagy-associated markers (PINK1 and PARK2) in lung epithelial cells, implying that mitophagy might play a role in protecting epithelial cells from hyperoxia-induced injury [72]. It is worth noting that the hyperoxia-induced ROS accumulation, mitochondrial damage and autophagy were also observed in pulmonary endothelial cells $[73,74]$. It has recently been reported that PINK1-mediated mitophagy is required for the ability of pulmonary endothelial cells to resist to hyperoxia [75]. It remains to be investigated whether autophagy functions in other types of lung cells under hyperoxia.

\subsection{The Protective Roles of Autophagy in Chlorine-Induced ALI}

Chlorine $\left(\mathrm{Cl}_{2}\right)$, which is extensively used in industrial applications worldwide, is a common toxic inhalant [76]. $\mathrm{Cl}_{2}$ inhalation, depending on the dose and duration of exposure, may cause $\mathrm{ALI}$ and respiratory failure, and represents a significant public health problem [77]. $\mathrm{Cl}_{2}$ exposure to 
lung epithelial cells leads to mitochondrial dysfunction and ROS accumulation, which might be a major cause of lung injury [77]. Interestingly, autophagy can be induced to prevent mitochondrial damage, decrease inflammation, and ameliorate $\mathrm{Cl}_{2}$ toxicity [78]. This study suggests a protective role of autophagy in $\mathrm{Cl}_{2}$-induced lung injury, and implies that autophagy might represent a potential therapeutic target for the treatment of toxic $\mathrm{Cl}_{2}$ exposure. However, it lacks evidence of mitophagy in maintaining mitochondrial homeostasis, which merits further investigation. Moreover, autophagic alterations in $\mathrm{Cl}_{2}$-challenged pulmonary endothelial cells or AMs and their underlying mechanisms may also be critical to prevent lung injury, and remain poorly defined.

\section{The Protective Roles of Autophagy in Idiopathic Pulmonary Fibrosis (IPF)}

Idiopathic pulmonary fibrosis (IPF) is a chronic and fatal lung disease of unknown cause characterized by chronic lung inflammation, diffuse alveolar damage, the accumulation of fibroblasts and myofibroblasts, abundant collagen deposition and extracellular matrix proteins [79]. Decreased LC3-II expression and mTOR overactivation were observed in alveolar epithelial cells in bleomycin-induced pulmonary fibrosis mice model, as well as lung tissues from IPF patients compared to normal counterparts, suggesting impaired autophagic activity in IPF [80-83]. The compromised autophagy is due, in part, to the activation of IL-17A in lung epithelial cells during the fibrotic process. IL-17A stimulation activates the PI3K-glycogen synthase kinase $3 \beta$ (GSK-3 $\beta$ ) signaling pathway to inhibit Bcl-2 degradation, leading to the suppression of autophagy. Neutralization of IL-17A effectively induces autophagy, enhances collagen degradation, and decreases bleomycin-induced pulmonary fibrosis [84,85]. Moreover, Atg4b-deficient mice display reduced autophagy induction, increased inflammatory response, augmented apoptosis and hyperproliferation of alveolar and bronchiolar epithelial cells, thereby increasing collagen accumulation and exaggerating bleomycin-induced pulmonary fibrosis [86]. In addition, Atg7 deficiency in endothelial cells impairs autophagic flux, upregulates TGF- $\beta$ signaling, and promotes the endothelial-to-mesenchymal transition for fibroblast formation, leading to more extensive and severe fibrosis in bleomycin-challenged mice [87]. These studies suggest a protective role of autophagy in IPF.

Indeed, stimulation of autophagy by rapamycin (an mTOR inhibitor promoting autophagic flux) significantly inhibits the fibrotic phenotype in bleomycin-induced pulmonary fibrosis. However, this protective effect of rapamycin can be partially reversed by chloroquine (an inhibitor of autolysosome formation blocking autophagic flux) $[80,81,84,88]$. Our recent findings suggest that bleomycin can directly bind ANXA2 in lung epithelial cells to prevent the translocation of transcription factor EB (TFEB) into the nucleus, leading to TFEB inactivation and impeded autophagic flux, thereby inducing pulmonary fibrosis. Pharmacological activation of TFEB using Torin 1 accelerates autophagic flux and significantly ameliorates bleomycin-induced pulmonary fibrosis [83]. These studies suggest that the autophagic flux might be inhibited to facilitate fibrotic progression in lung endothelial and epithelial cells. Further studies are required to investigate the upstream mechanisms by which autophagic flux is dysregulated in lung endothelial and epithelial cells in IPF.

Autophagy alteration in fibroblasts has also been reported to be critical in human IPF pathogenesis. Interestingly, human IPF fibroblasts show reduced autophagy induction and decreased autophagic flux, due to mTOR activation or reduced FoxO3a-mediated LC3 transcription [89-91]. The defective autophagy is required for maintaining the cell death-resistant phenotype for the fibroblasts on collagen-rich matrix [90,91]. Considering the profibrotic role of autophagy in IPF fibroblasts, the use of autophagy activators for IPF treatment should be re-evaluated in a context-specific manner.

Emerging evidence reveals the critical roles of deregulated mitochondrial homeostasis in AECIIs, fibroblasts or AMs in the pathogenesis of IPF. For example, it was reported that dysmorphic and dysfunctional mitochondria are accumulated in AECIIs in the lungs of IPF patients [92]. The impaired mitochondria in AECIIs are associated with decreased levels of PINK1 and defective mitophagy in AECIIs. PINK1-deficient mice exhibit deregulated mitochondrial homeostasis and development of pulmonary fibrosis [92]. The expression of PARK2, another mitophagy-associated 
protein, is downregulated in the lung fibroblasts of IPF patients. PARK2 deficiency aggravates bleomycin-induced pulmonary fibrosis in mice through promoting PDGFR-PI3K-Akt-mediated myofibroblast differentiation and proliferation [93]. Pirfenidone, an FDA-approved agent for IPF treatment, exerts its anti-fibrotic effect partially by inducing PARK2-mediated mitophagy and inhibiting myofibroblast differentiation [94]. Different from the protective role of mitophagy in AECIIs or fibroblasts for IPF, mitophagy is increased in IPF AMs and is required for the development of pulmonary fibrosis. During fibrosis, Akt1 in AMs is activated to induce the generation of mitochondrial ROS, leading to stimulation of PARK2-mediated mitophagy [95]. The Akt1-mediated mitophagy induction contributes to apoptosis resistance of AMs, enables the expression of macrophage-derived TGF- $\beta 1$, and ultimately promotes fibroblast differentiation and progression of pulmonary fibrosis [95]. Given the contrary effects of mitophagy of different cell types in IPF pathogenesis, the manipulation of cell type-specific mitophagy, rather than global mitophagy, may achieve better therapeutic outcome for IPF treatment.

\section{The Protective and Deleterious Roles of Autophagy in COPD}

COPD is a pulmonary disorder characterized by excessive inflammation and airway obstruction (i.e., chronic bronchitis and emphysema) [96]. Cigarette smoke (CS) remains the key risk factor for COPD worldwide [96]. The molecular mechanisms underlying COPD pathogenesis remain incompletely understood. It has been shown that the expression of ATG proteins, such as LC3, is increased in lung tissues from COPD patients and mouse lung tissues subjected to CS exposure, suggesting an increase of autophagosome formation in COPD [97,98]. The increased autophagosome formation is correlated with a cumulative increase in autophagic flux, suggesting that the autophagy pathway in lung epithelial cells is activated in COPD $[28,99]$. The increased activity of autophagy caused by CS exposure is at least partially due to the decreased histone deacetylase (HDAC) -mediated Egr-1 inhibition, elevated PGF-JNK1-p38-TSC2-mediated mTOR inhibition, or upregulation of oxidative stress-induced growth inhibitor 1 (OSGIN1) [98,100-102]. In response to CS exposure, LC3 dissociates from the extrinsic apoptotic factor Fas, leading to apoptotic cell death of lung epithelial cells for emphysema progression [103]. The activation of autophagy is also observed in particulate matter (PM) -induced experimental COPD model, and Atg7 deficiency protects mice from PM-induced COPD [104]. In addition to lung epithelial cells, increased autophagy was also observed in CS-treated neutrophils. CS exposure induces autophagic cell death of neutrophils by activating PAFR-HMGB1-Beclin-1-Bcl-2 signaling, leading to the development of emphysema [105]. These studies indicate that autophagy stimulation with increased autophagic flux, either in lung epithelial cells or neutrophils, contributes to the development of COPD.

Interestingly, autophagy has been reported to regulate bronchial epithelial cell senescence in CS-induced senescence-associated COPD. CS exposure leads to autophagy inhibition in COPD patients, which might be, in part, due to the activation of the SIRT6-IGF-Akt-mTOR signaling pathway [106,107]. Autophagy inhibition by 3-MA results in increased senescence in human bronchial epithelial cells, whereas autophagy activation by Torin 1 significantly inhibits cell senescence, indicating that the insufficient autophagy accelerates bronchial epithelial cell senescence in COPD [106]. The CS-impaired autophagy is characterized by the enhanced formation of aggresome and resultant insufficient autophagic clearance (impaired aggrephagy) $[106,108,109]$. A possible mechanism of CS-impaired autophagy is the perinuclear aggresome sequestration of TFEB, the master regulator of autophagy. Activation of TFEB using gemfibrozil significantly decreases CS-induced formation of aggresome, resulting in the mitigation of COPD progression [110]. These studies suggest that CS exposure promotes the accumulation of aggresome bodies and consequent autophagy impairment, which accelerates bronchial epithelial cell senescence and exacerbates the development of COPD.

The pathogenesis of CS-induced COPD is also associated with elevated levels of ROS caused by mitochondrial damage [111]. PARK2 deficiency results in increased mitochondrial damage, enhanced ROS accumulation, and accelerated senescence of lung epithelial cells under CS exposure, suggesting 
that CS-induced PARK2-mediated mitophagy may attenuate cellular senescence and inhibit the progression of COPD [111,112]. However, a study from another group indicates that PINK1-regulated mitophagy promotes necroptosis and cell death in lung epithelial cells, thereby contributing to COPD development [23]. The different outcomes of mitophagy in regulating senescence or necroptosis probably depend on the injury degree in response to CS [23,111]. In addition to damaged mitochondria, CS-induced autophagy also regulates cilia length by selective consumption of cilia components (ciliophagy) in respiratory epithelial cells in COPD pathogenesis [28,29]. In contrast to mitophagy and ciliophagy, CS exposure leads to autophagy inhibition and xenophagy impairment in AMs. In smokers' AMs, the autophagy degradation is defective as evidenced by the accumulation of both LC3 and p62, which may explain the clinical issue of recurrent infections for smokers [113].

Collectively, it seems that different autophagy machineries are involved in COPD pathogenesis, and the roles of autophagy in COPD pathogenesis vary in different reports. One possibility is that autophagy machineries in different types of lung cells are differentially regulated. In addition, the period of CS exposure in animals or the stages in humans might also be critical to the roles of autophagy in CS-induced COPD. Further studies are needed to decipher the precise roles of autophagy in COPD.

\section{The Protective Roles of Autophagy in Tuberculosis}

Extensive studies have demonstrated the critical roles of autophagy in the pathogenesis of tuberculosis caused by Mycobacterium tuberculosis (Mtb) infection. Mtb could interfere with the fusion of autophagosome with lysosome to prevent autophagosome maturation and subsequent autolysosomal degradation in macrophages $[114,115]$. Stimulation of autophagy by rapamycin, IFN- $\gamma$ or vitamin D promotes autophagic flux, enabling autophagy-mediated clearance of Mtb $[114,116]$. In addition to suppressing $\mathrm{Mtb}$ growth, autophagy also contributes to the resolution of damaging inflammation [117]. Interestingly, autophagy in monocytes is also involved in Mtb defense, and induction of autophagy in monocytes could enhance the antimicrobial activity against Mtb $[118,119]$. Moreover, the $\mathrm{Mtb}$-eradicating role of autophagy was observed in dendritic cells and lung epithelial cells [120-122]. However, a recent study shows that myeloid cell-specific deficiency of Atg5, but not other ATG genes (including Atg3, Atg7, Atg12, Atg14L and Atg16L1), significantly provokes Mtb infection and hampers the survival of infected mice [123]. This study suggests that the canonical autophagy pathway may not play a major role in the pathogenesis of tuberculosis. Instead of autophagy induction, Atg5 functions in a protective manner for Mtb infection by preventing polymorphonuclear cell (PMN)-mediated immunopathology [123]. Therefore, a more in-depth evaluation of the role of autophagy in tuberculosis pathogenesis is needed.

\section{The Protective Roles of Autophagy in Cystic Fibrosis (CF)}

Cystic fibrosis (CF) is a life-threatening lung disease caused by a loss-of-function mutation of cystic fibrosis transmembrane conductance regulator (CFTR, F508del) [124,125]. It has been reported that CFTR deficiency causes defective autophagic flux in both human airway epithelial cells and nasal biopsies from CF patients, leading to the formation of aggresome through the production of ROS, upregulation of tissue transglutaminase (TG2), sequestration of the class III PI3K complex and subsequent accumulation of p62 [126,127]. This disruption of autophagic clearance also heightens the inflammatory response in CFTR-mutant cells [128]. In addition to the airway epithelial cells, defective autophagic degradation was also observed in macrophages with CFTR mutation. The decreased autophagic clearance subverts the bactericidal function of macrophages, consequently resulting in pathogen infection, such as Nontuberculous mycobacteria (NTM) and Burkholderia cenocepacia (B. cepacia) $[129,130]$. Induction of autophagy by rapamycin or clearance of aggresome by p62 deletion could markedly enhance the elimination of pathogens and ameliorate the associated inflammation [130,131]. Together, these studies suggest that autophagy is a survival mechanism in the pathogenesis of $\mathrm{CF}$, and pharmacological induction of autophagy might be a promising strategy to delay CF progression. 


\section{The Protective Roles of Autophagy in Pulmonary Arterial Hypertension (PAH)}

Pulmonary arterial hypertension (PAH) is a lethal syndrome characterized by elevated pulmonary arterial pressure with unclear etiology [132]. Hypoxia is known as a common cause of PAH. It has been reported that human lungs with PAH reveal elevated LC3B levels and increased autophagosomes compared to normal lungs. In addition, autophagy induction is promoted following hypoxia treatment in human pulmonary artery endothelial cells (PAECs). In a chronic hypoxia-induced PH model, LC3B knockout mice show apparent PAH phenotypes relative to wild-type mice [133]. These results suggest a protective function of autophagy in PAH pathogenesis. The stimulation of autophagy was also observed in pulmonary artery smooth muscle cells (PASMCs) in a rat PAH model induced by monocrotaline or hypoxia. Paradoxically, the inhibition of autophagy by chloroquine or k-opioid receptor exerts beneficial effects for PAH [134,135], implying that autophagy may contribute to the pathogenesis of PAH. The various roles of autophagy in PAH pathogenesis might be explained by the different cell types, approaches and models used in these studies.

\section{Conclusions and Perspectives}

Accumulating evidence demonstrates that autophagy is involved in the regulation of diverse biological functions, such as inflammatory response, redox balance, DNA damage repair, apoptosis, and necroptosis in different cell types in the lung, and thus plays crucial roles in pulmonary infection and inflammatory diseases, including ALI, IPF, COPD, tuberculosis, PAH, CF, etc. (Figure 2). Autophagy is initially known as a protective process in the pathogenesis of most lung diseases. Recent findings also support the notion that autophagy may promote the pathogenesis of lung diseases in certain contexts. The diverse roles of autophagy in lung disease pathogenesis might be due to the different types of lung diseases (ALI, IPF, COPD, tuberculosis, PAH, CF, etc.), the diverse stressors for the etiology (infection, CS exposure, the stimulus intensity, etc.), the various cell types in the lung (epithelial cells, endothelial cells, fibroblasts, neutrophils, AMs, etc.), and the different mechanisms underlying disease initiation and progression (cell death such as apoptosis and necroptosis, cellular senescence, fibroblast differentiation, DNA damage, etc.). In addition, the analysis methods, experimental approaches, reagents, and models with different cells and animals (e.g., age, sex) all contribute to the variations in the laboratories. Furthermore, selective autophagy, such as mitophagy, xenophagy, aggrephagy, and ciliophagy, has recently attracted much attention in the pathogenesis of human lung diseases. It remains unclear how cells orchestrate nonselective autophagy and selective autophagy during disease initiation and progression, and whether nonselective autophagy cross-talks with selective autophagy [22]. Moreover, the lack of autophagy inhibitors to specifically target nonselective autophagy and selective autophagy in a given lung cell type also remains a major challenge for therapeutic intervention. Finally, some of the previous studies (especially those in vivo studies) only examined LC3-II accumulation which might be a result of the activation or inhibition of autophagic flux-mediated degradation. Therefore, the non-unified interpretation of autophagy activation and suppression remains a major problem for the evaluation of the exact roles of autophagy in pathological or therapeutic aspects. Careful consideration of the autophagy activity is needed to achieve a better and deeper understanding of the role of autophagy in lung disease pathogenesis for the development of potential therapeutic strategies.

Author Contributions: K.W., Y.C., P.J.Z., P.L. and M.W. reviewed the literature and co-wrote the manuscript; N.X. and M.W. revised the manuscript.

Funding: This work was supported by the Chinese NSFC (81602194 and 81872277), US National Institute of Health (R01 AI101973-04, R01 AI138203-01 and P20 GM113123 to M.W.), and the Fundamental Research Funds for the central Universities.

Conflicts of Interest: The authors declare no conflict of interest. 


\section{References}

1. Klionsky, D.J.; Abdelmohsen, K.; Abe, A.; Abedin, M.J.; Abeliovich, H.; Acevedo Arozena, A.; Adachi, H.; Adams, C.M.; Adams, P.D.; Adeli, K.; et al. Guidelines for the use and interpretation of assays for monitoring autophagy (3rdedition). Autophagy 2016, 12, 1-222. [CrossRef] [PubMed]

2. Gatica, D.; Lahiri, V.; Klionsky, D.J. Cargo recognition and degradation by selective autophagy. Nat. Cell Biol. 2018, 20, 233-242. [CrossRef] [PubMed]

3. Anding, A.L.; Baehrecke, E.H. Cleaning House: Selective Autophagy of Organelles. Dev. Cell 2017, 41, 10-22. [CrossRef] [PubMed]

4. Green, D.R.; Levine, B. To be or not to be? How selective autophagy and cell death govern cell fate. Cell 2014, 157, 65-75. [CrossRef] [PubMed]

5. Morel, E.; Mehrpour, M.; Botti, J.; Dupont, N.; Hamai, A.; Nascimbeni, A.C.; Codogno, P. Autophagy: A Druggable Process. Annu. Rev. Pharmacol. Toxicol. 2017, 57, 375-398. [CrossRef] [PubMed]

6. Ryter, S.W.; Nakahira, K.; Haspel, J.A.; Choi, A.M. Autophagy in pulmonary diseases. Annu. Rev. Physiol. 2012, 74, 377-401. [CrossRef] [PubMed]

7. Bhattacharya, J.; Matthay, M.A. Regulation and repair of the alveolar-capillary barrier in acute lung injury. Annu. Rev. Physiol. 2013, 75, 593-615. [CrossRef]

8. Nakahira, K.; Choi, A.M. Autophagy: A potential therapeutic target in lung diseases. Am. J. Physiol. Lung Cell. Mol. Physiol. 2013, 305, L93-L107. [CrossRef]

9. Nakahira, K.; Cloonan, S.M.; Mizumura, K.; Choi, A.M.; Ryter, S.W. Autophagy: A crucial moderator of redox balance, inflammation, and apoptosis in lung disease. Antioxid. Redox Signal. 2014, 20, 474-494. [CrossRef]

10. Haspel, J.A.; Choi, A.M. Autophagy: A core cellular process with emerging links to pulmonary disease. Am. J. Respir. Crit. Care Med. 2011, 184, 1237-1246. [CrossRef]

11. Aggarwal, S.; Mannam, P.; Zhang, J. Differential regulation of autophagy and mitophagy in pulmonary diseases. Am. J. Physiol. Lung Cell. Mol. Physiol. 2016, 311, L433-L452. [CrossRef] [PubMed]

12. Nakahira, K.; Pabon Porras, M.A.; Choi, A.M. Autophagy in Pulmonary Diseases. Am. J. Respir. Crit. Care Med. 2016, 194, 1196-1207. [CrossRef] [PubMed]

13. Antonioli, M.; Di Rienzo, M.; Piacentini, M.; Fimia, G.M. Emerging Mechanisms in Initiating and Terminating Autophagy. Trends Biochem. Sci. 2017, 42, 28-41. [CrossRef] [PubMed]

14. Marino, G.; Niso-Santano, M.; Baehrecke, E.H.; Kroemer, G. Self-consumption: The interplay of autophagy and apoptosis. Nat. Rev. Mol. Cell Biol. 2014, 15, 81-94. [CrossRef] [PubMed]

15. Zhang, L.; Wang, K.; Lei, Y.; Li, Q.; Nice, E.C.; Huang, C. Redox signaling: Potential arbitrator of autophagy and apoptosis in therapeutic response. Free Radic. Biol. Med. 2015, 89, 452-465. [CrossRef] [PubMed]

16. Kwon, Y.T.; Ciechanover, A. The Ubiquitin Code in the Ubiquitin-Proteasome System and Autophagy. Trends Biochem. Sci. 2017, 42, 873-886. [CrossRef] [PubMed]

17. Ichimura, Y.; Kirisako, T.; Takao, T.; Satomi, Y.; Shimonishi, Y.; Ishihara, N.; Mizushima, N.; Tanida, I.; Kominami, E.; Ohsumi, M.; et al. A ubiquitin-like system mediates protein lipidation. Nature 2000, 408, 488-492. [CrossRef] [PubMed]

18. Shen, H.M.; Mizushima, N. At the end of the autophagic road: An emerging understanding of lysosomal functions in autophagy. Trends Biochem. Sci. 2014, 39, 61-71. [CrossRef] [PubMed]

19. Moreau, K.; Renna, M.; Rubinsztein, D.C. Connections between SNAREs and autophagy. Trends Biochem. Sci. 2013, 38, 57-63. [CrossRef]

20. Pickles, S.; Vigie, P.; Youle, R.J. Mitophagy and Quality Control Mechanisms in Mitochondrial Maintenance. Curr. Biol. 2018, 28, R170-R185. [CrossRef]

21. Sui, X.; Liang, X.; Chen, L.; Guo, C.; Han, W.; Pan, H.; Li, X. Bacterial xenophagy and its possible role in cancer: A potential antimicrobial strategy for cancer prevention and treatment. Autophagy 2017, 13, $237-247$. [CrossRef] [PubMed]

22. Mizumura, K.; Cloonan, S.; Choi, M.E.; Hashimoto, S.; Nakahira, K.; Ryter, S.W.; Choi, A.M. Autophagy: Friend or Foe in Lung Disease? Ann. Am. Thorac. Soc. 2016, 13, S40-S47. [PubMed]

23. Mizumura, K.; Cloonan, S.M.; Nakahira, K.; Bhashyam, A.R.; Cervo, M.; Kitada, T.; Glass, K.; Owen, C.A.; Mahmood, A.; Washko, G.R.; et al. Mitophagy-dependent necroptosis contributes to the pathogenesis of COPD. J. Clin. Investig. 2014, 124, 3987-4003. [CrossRef] 
24. Sentelle, R.D.; Senkal, C.E.; Jiang, W.; Ponnusamy, S.; Gencer, S.; Selvam, S.P.; Ramshesh, V.K.; Peterson, Y.K.; Lemasters, J.J.; Szulc, Z.M.; et al. Ceramide targets autophagosomes to mitochondria and induces lethal mitophagy. Nat. Chem. Biol. 2012, 8, 831-838. [CrossRef] [PubMed]

25. Liu, B.; Fang, M.; Hu, Y.; Huang, B.; Li, N.; Chang, C.; Huang, R.; Xu, X.; Yang, Z.; Chen, Z.; et al. Hepatitis B virus $X$ protein inhibits autophagic degradation by impairing lysosomal maturation. Autophagy 2014, 10, 416-430. [CrossRef] [PubMed]

26. Sir, D.; Tian, Y.; Chen, W.L.; Ann, D.K.; Yen, T.S.; Ou, J.H. The early autophagic pathway is activated by hepatitis B virus and required for viral DNA replication. Proc. Natl. Acad. Sci. USA 2010, 107, 4383-4388. [CrossRef] [PubMed]

27. Deretic, V.; Levine, B. Autophagy, immunity, and microbial adaptations. Cell Host Microbe 2009, 5, 527-549. [CrossRef]

28. Lam, H.C.; Cloonan, S.M.; Bhashyam, A.R.; Haspel, J.A.; Singh, A.; Sathirapongsasuti, J.F.; Cervo, M.; Yao, H.; Chung, A.L.; Mizumura, K.; et al. Histone deacetylase 6-mediated selective autophagy regulates COPD-associated cilia dysfunction. J. Clin. Investig. 2013, 123, 5212-5230. [CrossRef]

29. Cloonan, S.M.; Lam, H.C.; Ryter, S.W.; Choi, A.M. "Ciliophagy": The consumption of cilia components by autophagy. Autophagy 2014, 10, 532-534. [CrossRef]

30. Matute-Bello, G.; Frevert, C.W.; Martin, T.R. Animal models of acute lung injury. Am. J. Physiol. Lung Cell. Mol. Physiol. 2008, 295, L379-L399. [CrossRef]

31. Lang, J.D.; McArdle, P.J.; O’Reilly, P.J.; Matalon, S. Oxidant-antioxidant balance in acute lung injury. Chest 2002, 122, 314S-320S. [CrossRef] [PubMed]

32. Li, Z.Y.; Wu, Y.F.; Xu, X.C.; Zhou, J.S.; Wang, Y.; Shen, H.H.; Chen, Z.H. Autophagy as a double-edged sword in pulmonary epithelial injury: A review and perspective. Am. J. Physiol. Lung Cell. Mol. Physiol. 2017, 313, L207-L217. [CrossRef] [PubMed]

33. Yuan, K.; Huang, C.; Fox, J.; Laturnus, D.; Carlson, E.; Zhang, B.; Yin, Q.; Gao, H.; Wu, M. Autophagy plays an essential role in the clearance of Pseudomonas aeruginosa by alveolar macrophages. J. Cell Sci. 2012, 125, 507-515. [CrossRef] [PubMed]

34. Li, R.; Tan, S.; Yu, M.; Jundt, M.C.; Zhang, S.; Wu, M. Annexin A2 Regulates Autophagy in Pseudomonas aeruginosa Infection through the Akt1-mTOR-ULK1/2 Signaling Pathway. J. Immunol. 2015, 195, 3901-3911. [CrossRef] [PubMed]

35. Li, X.; He, S.; Zhou, X.; Ye, Y.; Tan, S.; Zhang, S.; Li, R.; Yu, M.; Jundt, M.C.; Hidebrand, A.; et al. Lyn Delivers Bacteria to Lysosomes for Eradication through TLR2-Initiated Autophagy Related Phagocytosis. PLoS Pathog. 2016, 12, e1005363. [CrossRef] [PubMed]

36. Jati, S.; Kundu, S.; Chakraborty, A.; Mahata, S.K.; Nizet, V.; Sen, M. Wnt5A Signaling Promotes Defense Against Bacterial Pathogens by Activating a Host Autophagy Circuit. Front. Immunol. 2018, 9, 679. [CrossRef]

37. Li, X.; Ye, Y.; Zhou, X.; Huang, C.; Wu, M. Atg7 enhances host defense against infection via downregulation of superoxide but upregulation of nitric oxide. J. Immunol. 2015, 194, 1112-1121. [CrossRef] [PubMed]

38. Jabir, M.S.; Ritchie, N.D.; Li, D.; Bayes, H.K.; Tourlomousis, P.; Puleston, D.; Lupton, A.; Hopkins, L.; Simon, A.K.; Bryant, C.; et al. Caspase-1 cleavage of the TLR adaptor TRIF inhibits autophagy and beta-interferon production during Pseudomonas aeruginosa infection. Cell Host Microbe 2014, 15, $214-227$. [CrossRef] [PubMed]

39. Jabir, M.S.; Hopkins, L.; Ritchie, N.D.; Ullah, I.; Bayes, H.K.; Li, D.; Tourlomousis, P.; Lupton, A.; Puleston, D.; Simon, A.K.; et al. Mitochondrial damage contributes to Pseudomonas aeruginosa activation of the inflammasome and is downregulated by autophagy. Autophagy 2015, 11, 166-182. [CrossRef]

40. Ye, Y.; Li, X.; Wang, W.; Ouedraogo, K.C.; Li, Y.; Gan, C.; Tan, S.; Zhou, X.; Wu, M. Atg7 deficiency impairs host defense against Klebsiella pneumoniae by impacting bacterial clearance, survival and inflammatory responses in mice. Am. J. Physiol. Lung Cell. Mol. Physiol. 2014, 307, L355-L363. [CrossRef]

41. Ye, Y.; Tan, S.; Zhou, X.; Li, X.; Jundt, M.C.; Lichter, N.; Hidebrand, A.; Dhasarathy, A.; Wu, M. Inhibition of p-IkappaBalpha Ubiquitylation by Autophagy-Related Gene 7 to Regulate Inflammatory Responses to Bacterial Infection. J. Infect. Dis. 2015, 212, 1816-1826. [CrossRef] [PubMed]

42. Papayannopoulos, V. Neutrophil extracellular traps in immunity and disease. Nat. Rev. Immunol. 2018, 18, 134-147. [CrossRef] [PubMed] 
43. Tripathi, J.K.; Sharma, A.; Sukumaran, P.; Sun, Y.; Mishra, B.B.; Singh, B.B.; Sharma, J. Oxidant sensor cation channel TRPM2 regulates neutrophil extracellular trap formation and protects against pneumoseptic bacterial infection. FASEB J. 2018. [CrossRef] [PubMed]

44. Sharma, A.; Simonson, T.J.; Jondle, C.N.; Mishra, B.B.; Sharma, J. Mincle-Mediated Neutrophil Extracellular Trap Formation by Regulation of Autophagy. J. Infect. Dis. 2017, 215, 1040-1048. [CrossRef] [PubMed]

45. Tang, D.; Kang, R.; Coyne, C.B.; Zeh, H.J.; Lotze, M.T. PAMPs and DAMPs: Signal 0s that spur autophagy and immunity. Immunol. Rev. 2012, 249, 158-175. [CrossRef] [PubMed]

46. Aguirre, A.; Lopez-Alonso, I.; Gonzalez-Lopez, A.; Amado-Rodriguez, L.; Batalla-Solis, E.; Astudillo, A.; Blazquez-Prieto, J.; Fernandez, A.F.; Galvan, J.A.; dos Santos, C.C.; et al. Defective autophagy impairs ATF3 activity and worsens lung injury during endotoxemia. J. Mol. Med. 2014, 92, 665-676. [CrossRef] [PubMed]

47. Zeng, M.; Sang, W.; Chen, S.; Chen, R.; Zhang, H.; Xue, F.; Li, Z.; Liu, Y.; Gong, Y.; Kong, X. 4-PBA inhibits LPS-induced inflammation through regulating ER stress and autophagy in acute lung injury models. Toxicol. Lett. 2017, 271, 26-37. [CrossRef]

48. Hu, Y.; Lou, J.; Mao, Y.Y.; Lai, T.W.; Liu, L.Y.; Zhu, C.; Zhang, C.; Liu, J.; Li, Y.Y.; Zhang, F.; et al. Activation of MTOR in pulmonary epithelium promotes LPS-induced acute lung injury. Autophagy 2016, 12, 2286-2299. [CrossRef]

49. Fan, K.; Lin, L.; Ai, Q.; Wan, J.; Dai, J.; Liu, G.; Tang, L.; Yang, Y.; Ge, P.; Jiang, R.; et al. LipopolysaccharideInduced Dephosphorylation of AMPK-Activated Protein Kinase Potentiates Inflammatory Injury via Repression of ULK1-Dependent Autophagy. Front. Immunol. 2018, 9, 1464. [CrossRef]

50. Zhang, D.; Zhou, J.; Ye, L.C.; Li, J.; Wu, Z.; Li, Y.; Li, C. Autophagy maintains the integrity of endothelial barrier in LPS-induced lung injury. J. Cell. Physiol. 2018, 233, 688-698. [CrossRef]

51. Dong, W.; He, B.; Qian, H.; Liu, Q.; Wang, D.; Li, J.; Wei, Z.; Wang, Z.; Xu, Z.; Wu, G.; et al. RAB26-dependent autophagy protects adherens junctional integrity in acute lung injury. Autophagy 2018, 14, 1677-1692. [CrossRef] [PubMed]

52. Slavin, S.A.; Leonard, A.; Grose, V.; Fazal, F.; Rahman, A. Autophagy inhibitor 3-methyladenine protects against endothelial cell barrier dysfunction in acute lung injury. Am. J. Physiol. Lung Cell. Mol. Physiol. 2018, 314, L388-L396. [CrossRef] [PubMed]

53. Guo, L.; Stripay, J.L.; Zhang, X.; Collage, R.D.; Hulver, M.; Carchman, E.H.; Howell, G.M.; Zuckerbraun, B.S.; Lee, J.S.; Rosengart, M.R. CaMKIalpha regulates AMP kinase-dependent, TORC-1-independent autophagy during lipopolysaccharide-induced acute lung neutrophilic inflammation. J. Immunol. 2013, 190, 3620-3628. [CrossRef] [PubMed]

54. Liu, H.; Zhou, K.; Liao, L.; Zhang, T.; Yang, M.; Sun, C. Lipoxin A4 receptor agonist BML-111 induces autophagy in alveolar macrophages and protects from acute lung injury by activating MAPK signaling. Respir. Res. 2018, 19, 243. [CrossRef] [PubMed]

55. Rudd, K.E.; Kissoon, N.; Limmathurotsakul, D.; Bory, S.; Mutahunga, B.; Seymour, C.W.; Angus, D.C.; West, T.E. The global burden of sepsis: Barriers and potential solutions. Crit. Care 2018, 22, 232. [CrossRef]

56. Yen, Y.T.; Yang, H.R.; Lo, H.C.; Hsieh, Y.C.; Tsai, S.C.; Hong, C.W.; Hsieh, C.H. Enhancing autophagy with activated protein $C$ and rapamycin protects against sepsis-induced acute lung injury. Surgery 2013, 153, 689-698. [CrossRef] [PubMed]

57. Lo, S.; Yuan, S.S.; Hsu, C.; Cheng, Y.J.; Chang, Y.F.; Hsueh, H.W.; Lee, P.H.; Hsieh, Y.C. Lc3 over-expression improves survival and attenuates lung injury through increasing autophagosomal clearance in septic mice. Ann. Surg. 2013, 257, 352-363. [CrossRef]

58. Mannam, P.; Shinn, A.S.; Srivastava, A.; Neamu, R.F.; Walker, W.E.; Bohanon, M.; Merkel, J.; Kang, M.J.; Dela Cruz, C.S.; Ahasic, A.M.; et al. MKK3 regulates mitochondrial biogenesis and mitophagy in sepsis-induced lung injury. Am. J. Physiol. Lung Cell. Mol. Physiol. 2014, 306, L604-L619. [CrossRef]

59. Pu, Q.; Gan, C.; Li, R.; Li, Y.; Tan, S.; Li, X.; Wei, Y.; Lan, L.; Deng, X.; Liang, H.; et al. Atg7 Deficiency Intensifies Inflammasome Activation and Pyroptosis in Pseudomonas Sepsis. J. Immunol. 2017, 198, 3205-3213. [CrossRef]

60. Park, S.Y.; Shrestha, S.; Youn, Y.J.; Kim, J.K.; Kim, S.Y.; Kim, H.J.; Park, S.H.; Ahn, W.G.; Kim, S.; Lee, M.G.; et al. Autophagy Primes Neutrophils for Neutrophil Extracellular Trap Formation during Sepsis. Am. J. Respir. Crit. Care Med. 2017, 196, 577-589. [CrossRef] 
61. Liu, F.; Nie, C.; Zhao, N.; Wang, Y.; Liu, Y.; Li, Y.; Zeng, Z.; Ding, C.; Shao, Q.; Qing, C.; et al. MiR-155 Alleviates Septic Lung Injury by Inducing Autophagy Via Inhibition of Transforming Growth Factor-beta-Activated Binding Protein 2. Shock 2017, 48, 61-68. [CrossRef] [PubMed]

62. Figueiredo, N.; Chora, A.; Raquel, H.; Pejanovic, N.; Pereira, P.; Hartleben, B.; Neves-Costa, A.; Moita, C.; Pedroso, D.; Pinto, A.; et al. Anthracyclines induce DNA damage response-mediated protection against severe sepsis. Immunity 2013, 39, 874-884. [CrossRef] [PubMed]

63. Lee, S.J.; Ryter, S.W.; Xu, J.F.; Nakahira, K.; Kim, H.P.; Choi, A.M.; Kim, Y.S. Carbon monoxide activates autophagy via mitochondrial reactive oxygen species formation. Am. J. Respir. Cell Mol. Biol. 2011, 45, 867-873. [CrossRef] [PubMed]

64. Lee, S.; Lee, S.J.; Coronata, A.A.; Fredenburgh, L.E.; Chung, S.W.; Perrella, M.A.; Nakahira, K.; Ryter, S.W.; Choi, A.M. Carbon monoxide confers protection in sepsis by enhancing beclin 1-dependent autophagy and phagocytosis. Antioxid. Redox Signal. 2014, 20, 432-442. [CrossRef] [PubMed]

65. Dias-Freitas, F.; Metelo-Coimbra, C.; Roncon-Albuquerque, R., Jr. Molecular mechanisms underlying hyperoxia acute lung injury. Respir. Med. 2016, 119, 23-28. [CrossRef] [PubMed]

66. Zaher, T.E.; Miller, E.J.; Morrow, D.M.; Javdan, M.; Mantell, L.L. Hyperoxia-induced signal transduction pathways in pulmonary epithelial cells. Free Radic. Biol. Med. 2007, 42, 897-908. [CrossRef] [PubMed]

67. Tanaka, A.; Jin, Y.; Lee, S.J.; Zhang, M.; Kim, H.P.; Stolz, D.B.; Ryter, S.W.; Choi, A.M. Hyperoxia-induced LC3B interacts with the Fas apoptotic pathway in epithelial cell death. Am. J. Respir. Cell Mol. Biol. 2012, 46, 507-514. [CrossRef]

68. Liang, X.; Wei, S.Q.; Lee, S.J.; Fung, J.K.; Zhang, M.; Tanaka, A.; Choi, A.M.; Jin, Y. p62 sequestosome 1/light chain $3 \mathrm{~b}$ complex confers cytoprotection on lung epithelial cells after hyperoxia. Am. J. Respir. Cell Mol. Biol. 2013, 48, 489-496. [CrossRef]

69. Zhang, L.; Zhao, S.; Yuan, L.J.; Wu, H.M.; Jiang, H.; Zhao, S.M.; Luo, G.; Xue, X.D. Autophagy regulates hyperoxia-induced intracellular accumulation of surfactant protein $\mathrm{C}$ in alveolar type II cells. Mol. Cell. Biochem. 2015, 408, 181-189. [CrossRef]

70. Zhang, L.; Zhao, S.; Yuan, L.; Wu, H.; Jiang, H.; Luo, G. Hyperoxia-mediated LC3B activation contributes to the impaired transdifferentiation of type II alveolar epithelial cells (AECIIs) to type I cells (AECIs). Clin. Exp. Pharmacol. Physiol. 2016, 43, 834-843. [CrossRef]

71. Ye, Y.; Lin, P.; Zhang, W.; Tan, S.; Zhou, X.; Li, R.; Pu, Q.; Koff, J.L.; Dhasarathy, A.; Ma, F.; et al. DNA Repair Interacts with Autophagy To Regulate Inflammatory Responses to Pulmonary Hyperoxia. J. Immunol. 2017, 198, 2844-2853. [CrossRef]

72. Narala, V.R.; Fukumoto, J.; Hernandez-Cuervo, H.; Patil, S.S.; Krishnamurthy, S.; Breitzig, M.; Galam, L.; Soundararajan, R.; Lockey, R.F.; Kolliputi, N. Akap1 genetic deletion increases the severity of hyperoxiainduced acute lung injury in mice. Am. J. Physiol. Lung Cell. Mol. Physiol. 2018, 314, L860-L870. [CrossRef]

73. Ma, C.; Beyer, A.M.; Durand, M.; Clough, A.V.; Zhu, D.; Norwood Toro, L.; Terashvili, M.; Ebben, J.D.; Hill, R.B.; Audi, S.H.; et al. Hyperoxia Causes Mitochondrial Fragmentation in Pulmonary Endothelial Cells by Increasing Expression of Pro-Fission Proteins. Arterioscler. Thromb. Vasc. Biol. 2018, 38, 622-635. [CrossRef]

74. Zhang, Y.; Jiang, G.; Sauler, M.; Lee, P.J. Lung endothelial HO-1 targeting in vivo using lentiviral miRNA regulates apoptosis and autophagy during oxidant injury. FASEB J. 2013, 27, 4041-4058. [CrossRef]

75. Zhang, Y.; Sauler, M.; Shinn, A.S.; Gong, H.; Haslip, M.; Shan, P.; Mannam, P.; Lee, P.J. Endothelial PINK1 mediates the protective effects of NLRP3 deficiency during lethal oxidant injury. J. Immunol. 2014, 192, 5296-5304. [CrossRef]

76. Evans, R.B. Chlorine: State of the art. Lung 2005, 183, 151-167. [CrossRef]

77. Carlisle, M.; Lam, A.; Svendsen, E.R.; Aggarwal, S.; Matalon, S. Chlorine-induced cardiopulmonary injury. Ann. N. Y. Acad. Sci. 2016, 1374, 159-167. [CrossRef]

78. Jurkuvenaite, A.; Benavides, G.A.; Komarova, S.; Doran, S.F.; Johnson, M.; Aggarwal, S.; Zhang, J.; Darley-Usmar, V.M.; Matalon, S. Upregulation of autophagy decreases chlorine-induced mitochondrial injury and lung inflammation. Free Radic. Biol. Med. 2015, 85, 83-94. [CrossRef]

79. Wolters, P.J.; Collard, H.R.; Jones, K.D. Pathogenesis of idiopathic pulmonary fibrosis. Annu. Rev. Pathol. 2014, 9, 157-179. [CrossRef]

80. Patel, A.S.; Lin, L.; Geyer, A.; Haspel, J.A.; An, C.H.; Cao, J.; Rosas, I.O.; Morse, D. Autophagy in idiopathic pulmonary fibrosis. PLoS ONE 2012, 7, e41394. [CrossRef] 
81. Gui, Y.S.; Wang, L.; Tian, X.; Li, X.; Ma, A.; Zhou, W.; Zeng, N.; Zhang, J.; Cai, B.; Zhang, H.; et al. mTOR Overactivation and Compromised Autophagy in the Pathogenesis of Pulmonary Fibrosis. PLoS ONE 2015, 10, e0138625. [CrossRef]

82. Araya, J.; Kojima, J.; Takasaka, N.; Ito, S.; Fujii, S.; Hara, H.; Yanagisawa, H.; Kobayashi, K.; Tsurushige, C.; Kawaishi, M.; et al. Insufficient autophagy in idiopathic pulmonary fibrosis. Am. J. Physiol. Lung Cell. Mol. Physiol. 2013, 304, L56-L69. [CrossRef]

83. Wang, K.; Zhang, T.; Lei, Y.; Li, X.; Jiang, J.; Lan, J.; Liu, Y.; Chen, H.; Gao, W.; Xie, N.; et al. Identification of ANXA2 (annexin A2) as a specific bleomycin target to induce pulmonary fibrosis by impeding TFEB-mediated autophagic flux. Autophagy 2018, 14, 269-282. [CrossRef]

84. Mi, S.; Li, Z.; Yang, H.Z.; Liu, H.; Wang, J.P.; Ma, Y.G.; Wang, X.X.; Liu, H.Z.; Sun, W.; Hu, Z.W. Blocking IL-17A promotes the resolution of pulmonary inflammation and fibrosis via TGF-beta1-dependent and -independent mechanisms. J. Immunol. 2011, 187, 3003-3014. [CrossRef]

85. Liu, H.; Mi, S.; Li, Z.; Hua, F.; Hu, Z.W. Interleukin 17A inhibits autophagy through activation of PIK3CA to interrupt the GSK3B-mediated degradation of BCL2 in lung epithelial cells. Autophagy 2013, 9, 730-742. [CrossRef]

86. Cabrera, S.; Maciel, M.; Herrera, I.; Nava, T.; Vergara, F.; Gaxiola, M.; Lopez-Otin, C.; Selman, M.; Pardo, A. Essential role for the ATG4B protease and autophagy in bleomycin-induced pulmonary fibrosis. Autophagy 2015, 11, 670-684. [CrossRef]

87. Singh, K.K.; Lovren, F.; Pan, Y.; Quan, A.; Ramadan, A.; Matkar, P.N.; Ehsan, M.; Sandhu, P.; Mantella, L.E.; Gupta, N.; et al. The essential autophagy gene ATG7 modulates organ fibrosis via regulation of endothelial-tomesenchymal transition. J. Biol. Chem. 2015, 290, 2547-2559. [CrossRef]

88. Yang, H.Z.; Wang, J.P.; Mi, S.; Liu, H.Z.; Cui, B.; Yan, H.M.; Yan, J.; Li, Z.; Liu, H.; Hua, F.; et al. TLR4 activity is required in the resolution of pulmonary inflammation and fibrosis after acute and chronic lung injury. $A m$. J. Pathol. 2012, 180, 275-292. [CrossRef]

89. Ricci, A.; Cherubini, E.; Scozzi, D.; Pietrangeli, V.; Tabbi, L.; Raffa, S.; Leone, L.; Visco, V.; Torrisi, M.R.; Bruno, P.; et al. Decreased expression of autophagic beclin 1 protein in idiopathic pulmonary fibrosis fibroblasts. J. Cell. Physiol. 2013, 228, 1516-1524. [CrossRef]

90. Romero, Y.; Bueno, M.; Ramirez, R.; Alvarez, D.; Sembrat, J.C.; Goncharova, E.A.; Rojas, M.; Selman, M.; Mora, A.L.; Pardo, A. mTORC1 activation decreases autophagy in aging and idiopathic pulmonary fibrosis and contributes to apoptosis resistance in IPF fibroblasts. Aging Cell 2016, 15, 1103-1112. [CrossRef]

91. Im, J.; Hergert, P.; Nho, R.S. Reduced FoxO3a expression causes low autophagy in idiopathic pulmonary fibrosis fibroblasts on collagen matrices. Am. J. Physiol. Lung Cell. Mol. Physiol. 2015, 309, L552-L561. [CrossRef]

92. Bueno, M.; Lai, Y.C.; Romero, Y.; Brands, J.; St Croix, C.M.; Kamga, C.; Corey, C.; Herazo-Maya, J.D.; Sembrat, J.; Lee, J.S.; et al. PINK1 deficiency impairs mitochondrial homeostasis and promotes lung fibrosis. J. Clin. Investig. 2015, 125, 521-538. [CrossRef]

93. Kobayashi, K.; Araya, J.; Minagawa, S.; Hara, H.; Saito, N.; Kadota, T.; Sato, N.; Yoshida, M.; Tsubouchi, K.; Kurita, Y.; et al. Involvement of PARK2-Mediated Mitophagy in Idiopathic Pulmonary Fibrosis Pathogenesis. J. Immunol. 2016, 197, 504-516. [CrossRef]

94. Kurita, Y.; Araya, J.; Minagawa, S.; Hara, H.; Ichikawa, A.; Saito, N.; Kadota, T.; Tsubouchi, K.; Sato, N.; Yoshida, M.; et al. Pirfenidone inhibits myofibroblast differentiation and lung fibrosis development during insufficient mitophagy. Respir. Res. 2017, 18, 114. [CrossRef]

95. Larson-Casey, J.L.; Deshane, J.S.; Ryan, A.J.; Thannickal, V.J.; Carter, A.B. Macrophage Akt1 Kinase-Mediated Mitophagy Modulates Apoptosis Resistance and Pulmonary Fibrosis. Immunity 2016, 44, 582-596. [CrossRef]

96. Tuder, R.M.; Petrache, I. Pathogenesis of chronic obstructive pulmonary disease. J. Clin. Investig. 2012, 122, 2749-2755. [CrossRef]

97. Ryter, S.W.; Chen, Z.H.; Kim, H.P.; Choi, A.M. Autophagy in chronic obstructive pulmonary disease: Homeostatic or pathogenic mechanism? Autophagy 2009, 5, 235-237. [CrossRef]

98. Chen, Z.H.; Kim, H.P.; Sciurba, F.C.; Lee, S.J.; Feghali-Bostwick, C.; Stolz, D.B.; Dhir, R.; Landreneau, R.J.; Schuchert, M.J.; Yousem, S.A.; et al. Egr-1 regulates autophagy in cigarette smoke-induced chronic obstructive pulmonary disease. PLOS ONE 2008, 3, e3316. [CrossRef]

99. Kim, H.P.; Wang, X.; Chen, Z.H.; Lee, S.J.; Huang, M.H.; Wang, Y.; Ryter, S.W.; Choi, A.M. Autophagic proteins regulate cigarette smoke-induced apoptosis: Protective role of heme oxygenase-1. Autophagy 2008, 4, 887-895. [CrossRef] 
100. Wang, Y.; Liu, J.; Zhou, J.S.; Huang, H.Q.; Li, Z.Y.; Xu, X.C.; Lai, T.W.; Hu, Y.; Zhou, H.B.; Chen, H.P.; et al. MTOR Suppresses Cigarette Smoke-Induced Epithelial Cell Death and Airway Inflammation in Chronic Obstructive Pulmonary Disease. J. Immunol. 2018, 200, 2571-2580. [CrossRef]

101. Hou, H.H.; Cheng, S.L.; Chung, K.P.; Kuo, M.Y.; Yeh, C.C.; Chang, B.E.; Lu, H.H.; Wang, H.C.; Yu, C.J. Elastase induces lung epithelial cell autophagy through placental growth factor: A new insight of emphysema pathogenesis. Autophagy 2014, 10, 1509-1521. [CrossRef]

102. Wang, G.; Zhou, H.; Strulovici-Barel, Y.; Al-Hijji, M.; Ou, X.; Salit, J.; Walters, M.S.; Staudt, M.R.; Kaner, R.J.; Crystal, R.G. Role of OSGIN1 in mediating smoking-induced autophagy in the human airway epithelium. Autophagy 2017, 13, 1205-1220. [CrossRef]

103. Chen, Z.H.; Lam, H.C.; Jin, Y.; Kim, H.P.; Cao, J.; Lee, S.J.; Ifedigbo, E.; Parameswaran, H.; Ryter, S.W.; Choi, A.M. Autophagy protein microtubule-associated protein 1 light chain-3B (LC3B) activates extrinsic apoptosis during cigarette smoke-induced emphysema. Proc. Natl. Acad. Sci. USA 2010, 107, 18880-18885. [CrossRef]

104. Li, X.; Yang, H.; Sun, H.; Lu, R.; Zhang, C.; Gao, N.; Meng, Q.; Wu, S.; Wang, S.; Aschner, M.; et al. Taurine ameliorates particulate matter-induced emphysema by switching on mitochondrial NADH dehydrogenase genes. Proc. Natl. Acad. Sci. USA 2017, 114, E9655-E9664. [CrossRef]

105. Lv, X.X.; Liu, S.S.; Li, K.; Cui, B.; Liu, C.; Hu, Z.W. Cigarette smoke promotes COPD by activating platelet-activating factor receptor and inducing neutrophil autophagic death in mice. Oncotarget 2017, 8, 74720-74735. [CrossRef]

106. Fujii, S.; Hara, H.; Araya, J.; Takasaka, N.; Kojima, J.; Ito, S.; Minagawa, S.; Yumino, Y.; Ishikawa, T.; Numata, T.; et al. Insufficient autophagy promotes bronchial epithelial cell senescence in chronic obstructive pulmonary disease. Oncoimmunology 2012, 1, 630-641. [CrossRef]

107. Takasaka, N.; Araya, J.; Hara, H.; Ito, S.; Kobayashi, K.; Kurita, Y.; Wakui, H.; Yoshii, Y.; Yumino, Y.; Fujii, S.; et al. Autophagy induction by SIRT6 through attenuation of insulin-like growth factor signaling is involved in the regulation of human bronchial epithelial cell senescence. J. Immunol. 2014, 192, 958-968. [CrossRef]

108. Tran, I.; Ji, C.; Ni, I.; Min, T.; Tang, D.; Vij, N. Role of Cigarette Smoke-Induced Aggresome Formation in Chronic Obstructive Pulmonary Disease-Emphysema Pathogenesis. Am. J. Respir. Cell Mol. Biol. 2015, 53, 159-173. [CrossRef]

109. Bodas, M.; Pehote, G.; Silverberg, D.; Gulbins, E.; Vij, N. Autophagy augmentation alleviates cigarette smoke-induced CFTR-dysfunction, ceramide-accumulation and COPD-emphysema pathogenesis. Free Radic. Biol. Med. 2018, 131, 81-97. [CrossRef]

110. Bodas, M.; Patel, N.; Silverberg, D.; Walworth, K.; Vij, N. Master Autophagy Regulator Transcription Factor EB Regulates Cigarette Smoke-Induced Autophagy Impairment and Chronic Obstructive Pulmonary Disease-Emphysema Pathogenesis. Antioxid. Redox Signal. 2017, 27, 150-167. [CrossRef]

111. Ito, S.; Araya, J.; Kurita, Y.; Kobayashi, K.; Takasaka, N.; Yoshida, M.; Hara, H.; Minagawa, S.; Wakui, H.; Fujii, S.; et al. PARK2-mediated mitophagy is involved in regulation of HBEC senescence in COPD pathogenesis. Autophagy 2015, 11, 547-559. [CrossRef]

112. Araya, J.; Tsubouchi, K.; Sato, N.; Ito, S.; Minagawa, S.; Hara, H.; Hosaka, Y.; Ichikawa, A.; Saito, N.; Kadota, T.; et al. PRKN-regulated mitophagy and cellular senescence during COPD pathogenesis. Autophagy 2018. [CrossRef]

113. Monick, M.M.; Powers, L.S.; Walters, K.; Lovan, N.; Zhang, M.; Gerke, A.; Hansdottir, S.; Hunninghake, G.W. Identification of an autophagy defect in smokers' alveolar macrophages. J. Immunol. 2010, 185, 5425-5435. [CrossRef]

114. Gutierrez, M.G.; Master, S.S.; Singh, S.B.; Taylor, G.A.; Colombo, M.I.; Deretic, V. Autophagy is a defense mechanism inhibiting BCG and Mycobacterium tuberculosis survival in infected macrophages. Cell 2004, 119, 753-766. [CrossRef]

115. Chandra, P.; Kumar, D. Selective autophagy gets more selective: Uncoupling of autophagy flux and xenophagy flux in Mycobacterium tuberculosis-infected macrophages. Autophagy 2016, 12, 608-609. [CrossRef]

116. Campbell, G.R.; Spector, S.A. Vitamin D inhibits human immunodeficiency virus type 1 and Mycobacterium tuberculosis infection in macrophages through the induction of autophagy. PLoS Pathog. 2012, 8, e1002689. [CrossRef] 
117. Castillo, E.F.; Dekonenko, A.; Arko-Mensah, J.; Mandell, M.A.; Dupont, N.; Jiang, S.; Delgado-Vargas, M.; Timmins, G.S.; Bhattacharya, D.; Yang, H.; et al. Autophagy protects against active tuberculosis by suppressing bacterial burden and inflammation. Proc. Natl. Acad. Sci. USA 2012, 109, E3168-E3176. [CrossRef]

118. Kim, J.K.; Lee, H.M.; Park, K.S.; Shin, D.M.; Kim, T.S.; Kim, Y.S.; Suh, H.W.; Kim, S.Y.; Kim, I.S.; Kim, J.M.; et al. MIR144* inhibits antimicrobial responses against Mycobacterium tuberculosis in human monocytes and macrophages by targeting the autophagy protein DRAM2. Autophagy 2017, 13, 423-441. [CrossRef]

119. Tateosian, N.L.; Pellegrini, J.M.; Amiano, N.O.; Rolandelli, A.; Casco, N.; Palmero, D.J.; Colombo, M.I.; Garcia, V.E. IL17A augments autophagy in Mycobacterium tuberculosis-infected monocytes from patients with active tuberculosis in association with the severity of the disease. Autophagy 2017, 13, 1191-1204. [CrossRef]

120. Etna, M.P.; Sinigaglia, A.; Grassi, A.; Giacomini, E.; Romagnoli, A.; Pardini, M.; Severa, M.; Cruciani, M.; Rizzo, F.; Anastasiadou, E.; et al. Mycobacterium tuberculosis-induced miR-155 subverts autophagy by targeting ATG3 in human dendritic cells. PLoS Pathog. 2018, 14, e1006790. [CrossRef]

121. Fine, K.L.; Metcalfe, M.G.; White, E.; Virji, M.; Karls, R.K.; Quinn, F.D. Involvement of the autophagy pathway in trafficking of Mycobacterium tuberculosis bacilli through cultured human type II epithelial cells. Cell. Microbiol. 2012, 14, 1402-1414. [CrossRef]

122. Romagnoli, A.; Etna, M.P.; Giacomini, E.; Pardini, M.; Remoli, M.E.; Corazzari, M.; Falasca, L.; Goletti, D.; Gafa, V.; Simeone, R.; et al. ESX-1 dependent impairment of autophagic flux by Mycobacterium tuberculosis in human dendritic cells. Autophagy 2012, 8, 1357-1370. [CrossRef] [PubMed]

123. Kimmey, J.M.; Huynh, J.P.; Weiss, L.A.; Park, S.; Kambal, A.; Debnath, J.; Virgin, H.W.; Stallings, C.L. Unique role for ATG5 in neutrophil-mediated immunopathology during M. tuberculosis infection. Nature 2015, 528, 565-569. [CrossRef]

124. Villella, V.R.; Esposito, S.; Bruscia, E.M.; Maiuri, M.C.; Raia, V.; Kroemer, G.; Maiuri, L. Targeting the Intracellular Environment in Cystic Fibrosis: Restoring Autophagy as a Novel Strategy to Circumvent the CFTR Defect. Front. Pharmacol. 2013, 4, 1. [CrossRef] [PubMed]

125. Junkins, R.D.; McCormick, C.; Lin, T.J. The emerging potential of autophagy-based therapies in the treatment of cystic fibrosis lung infections. Autophagy 2014, 10, 538-547. [CrossRef]

126. Luciani, A.; Villella, V.R.; Esposito, S.; Brunetti-Pierri, N.; Medina, D.; Settembre, C.; Gavina, M.; Pulze, L.; Giardino, I.; Pettoello-Mantovani, M.; et al. Defective CFTR induces aggresome formation and lung inflammation in cystic fibrosis through ROS-mediated autophagy inhibition. Nat. Cell Biol. 2010, 12, 863-875. [CrossRef] [PubMed]

127. Luciani, A.; Villella, V.R.; Esposito, S.; Gavina, M.; Russo, I.; Silano, M.; Guido, S.; Pettoello-Mantovani, M.; Carnuccio, R.; Scholte, B.; et al. Targeting autophagy as a novel strategy for facilitating the therapeutic action of potentiators on DeltaF508 cystic fibrosis transmembrane conductance regulator. Autophagy 2012, 8 , 1657-1672. [CrossRef]

128. Mayer, M.L.; Blohmke, C.J.; Falsafi, R.; Fjell, C.D.; Madera, L.; Turvey, S.E.; Hancock, R.E. Rescue of dysfunctional autophagy attenuates hyperinflammatory responses from cystic fibrosis cells. J. Immunol. 2013, 190, 1227-1238. [CrossRef]

129. Renna, M.; Schaffner, C.; Brown, K.; Shang, S.; Tamayo, M.H.; Hegyi, K.; Grimsey, N.J.; Cusens, D.; Coulter, S.; Cooper, J.; et al. Azithromycin blocks autophagy and may predispose cystic fibrosis patients to mycobacterial infection. J. Clin. Investig. 2011, 121, 3554-3563. [CrossRef]

130. Abdulrahman, B.A.; Khweek, A.A.; Akhter, A.; Caution, K.; Kotrange, S.; Abdelaziz, D.H.; Newland, C.; Rosales-Reyes, R.; Kopp, B.; McCoy, K.; et al. Autophagy stimulation by rapamycin suppresses lung inflammation and infection by Burkholderia cenocepacia in a model of cystic fibrosis. Autophagy 2011, 7, 1359-1370. [CrossRef]

131. Abdulrahman, B.A.; Khweek, A.A.; Akhter, A.; Caution, K.; Tazi, M.; Hassan, H.; Zhang, Y.; Rowland, P.D.; Malhotra, S.; Aeffner, F.; et al. Depletion of the ubiquitin-binding adaptor molecule SQSTM1/p62 from macrophages harboring cftr DeltaF508 mutation improves the delivery of Burkholderia cenocepacia to the autophagic machinery. J. Biol. Chem. 2013, 288, 2049-2058. [CrossRef] [PubMed]

132. Lai, Y.C.; Potoka, K.C.; Champion, H.C.; Mora, A.L.; Gladwin, M.T. Pulmonary arterial hypertension: The clinical syndrome. Circ. Res. 2014, 115, 115-130. [CrossRef] [PubMed] 
133. Lee, S.J.; Smith, A.; Guo, L.; Alastalo, T.P.; Li, M.; Sawada, H.; Liu, X.; Chen, Z.H.; Ifedigbo, E.; Jin, Y.; et al. Autophagic protein LC3B confers resistance against hypoxia-induced pulmonary hypertension. Am. J. Respir. Crit. Care Med. 2011, 183, 649-658. [CrossRef] [PubMed]

134. Long, L.; Yang, X.; Southwood, M.; Lu, J.; Marciniak, S.J.; Dunmore, B.J.; Morrell, N.W. Chloroquine prevents progression of experimental pulmonary hypertension via inhibition of autophagy and lysosomal bone morphogenetic protein type II receptor degradation. Circ. Res. 2013, 112, 1159-1170. [CrossRef] [PubMed]

135. Zhou, Y.; Wang, Y.; Wang, X.; Tian, X.; Zhang, S.; Yang, F.; Guo, H.; Fan, R.; Feng, N.; Jia, M.; et al. The Protective Effects of Kappa-Opioid Receptor Stimulation in Hypoxic Pulmonary Hypertension Involve Inhibition of Autophagy Through the AMPK-MTOR Pathway. Cell. Physiol. Biochem. 2017, 44, 1965-1979. [CrossRef] [PubMed]

(C) 2019 by the authors. Licensee MDPI, Basel, Switzerland. This article is an open access article distributed under the terms and conditions of the Creative Commons Attribution (CC BY) license (http:/ / creativecommons.org/licenses/by/4.0/). 